\title{
Mechanism of the Arene-Limited Nondirected C-H Activation of Arenes with Palladium: A Combined Experimental and Theoretical Study
}

\author{
Philipp Wedi, ${ }^{\dagger}$ Klaus Bergander, $\neq$ Christian Mück-Lichtenfeld, ${ }^{*}, \neq$ and Manuel van Gemmeren $*,+$, \\ †Max Planck Institute for Chemical Energy Conversion, Stiftstraße 34-36, 45470 Mülheim an der Ruhr, Germany \\ ‡Westfälische Wilhelms-Universität Münster, Organisch-Chemisches Institut, Correnstraße 40, 48149 Münster, \\ Germany
}

\begin{abstract}
Recently, synthetic methods have been discovered which enable the directing group-free C-H activation of arenes with palladium-catalysts and do not require an excess of the arene substrate. By overcoming this long standing challenge, such methods have now become suitable for the functionalization of complex organic molecules. The key to success in several of these transformations has been the use of two complementary ligands, an $N$-acyl amino acid and an $N$ heterocycle. Further applications of this design principle will likely require the guidance by a profound mechanistic understanding. This prompted us to engage in a detailed experimental and computational mechanistic study of the dual ligand enabled C-H activation of arenes. Based on comprehensive kinetic experiments, (CID-)MS, (DOSY-)NMR, and DFT calculations we find that a 1:1:1 complex of palladium and the two ligands is indeed the active species that enables a partially rate-limiting concerted $\mathrm{C}-\mathrm{H}$ activation as part of a $\mathrm{Pd}^{0} / \mathrm{Pd}^{\mathrm{II}}$-cycle. Our study highlights the importance of catalyst speciation and allows us to rationalize the role of each ligand as well as the observed regioselectivities. These findings are expected to be highly useful for further method development using this powerful class of catalysts.
\end{abstract}

\section{INTRODUCTION}

The prevalence of aromatic cores in natural products and bioactive molecules leads to a continued interest in the development of methods to access such compounds efficiently and in the case of multisubstituted arenes, selectively generate the desired regioisomer. In this context the use of $\mathrm{C}-\mathrm{H}$ activation has been identified as an enabling technology, often complementing the selectivity patterns obtained in classic aromatic substitution reactions and allowing for the formation of otherwise challenging bonds. ${ }^{1-}$ 8

Many methods developed in this field rely on directing effects ${ }^{9}$ to address the two critical challenges associated with $\mathrm{C}-\mathrm{H}$ activation: the low reactivity of $\mathrm{C}-\mathrm{H}$ bonds and the control of regioselectivity. ${ }^{10-24}$ With unbiased substrates, catalyst design has to be used to achieve the desired reactivity. Such nondirected (non-chelate-assisted) methods offer an inherently orthogonal selectivity pattern and potentially broader applicability due to their independence from directing groups. ${ }^{25-28}$

However, nondirected methods have faced a longstanding challenge: in order to achieve reactivity, the arene substrate had to be used in excess, often as (co)solvent. Intensive studies over the last two decades have led to the development of methods overcoming this limitation. Seminal work by the groups of Maleczka, Smith and coworkers, as well as Hartwig, Miyaura, Ishiyama and coworkers, enabled the arene-limited nondirected borylation of unbiased arenes. Following this work, a variety of synthetic methods mostly based on Ir- and Rhcatalysis has been reported, which have proven particularly useful for late-stage C-heteroatom bond formation and soon found widespread application even on an industrial scale. ${ }^{29-}$ ${ }^{34}$ The regioselectivity of these transformations is governed by a combination of steric and electronic control, which can be tuned by catalyst design, and enables the highly selective synthesis of product motives that are otherwise not easily accessible. ${ }^{35,36}$

In contrast, Pd-catalysis has remained underdeveloped and until recently no general methods were available that allowed for the arene-limited nondirected formation of aryl-palladium species.

Scheme 1. Milestones for the Nondirected AreneLimited C-H Activation of Arenes.

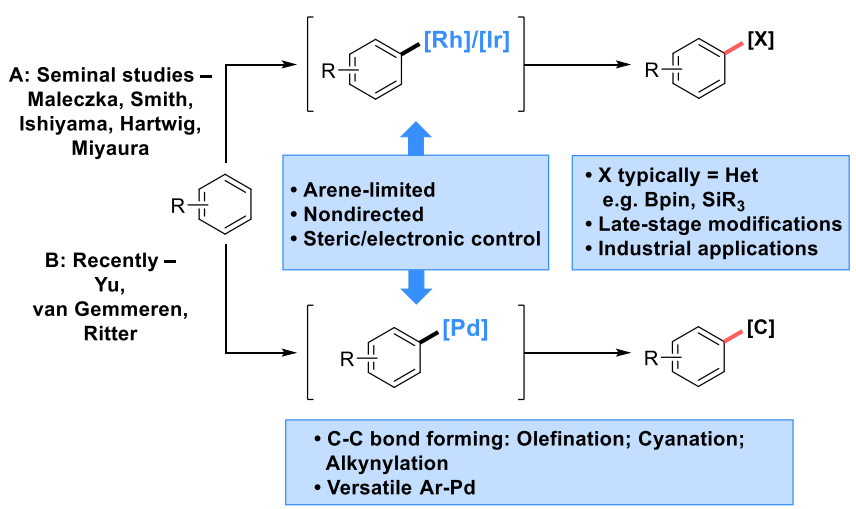


In light of the prominent role of palladium-catalysis for C$\mathrm{C}$ bond forming processes, we became interested in developing a catalyst capable of achieving such an activation and thereby unlocking a synthetic potential complementary to the Ir- and Rh-based methods.

Using the Fujiwara-Moritani reaction as model reaction, ${ }^{37-40}$ the group of $\mathrm{Yu}$ et al. and ourselves recently developed the first broadly applicable palladium catalysts for the arene-limited nondirected $\mathrm{C}-\mathrm{H}$ activation of arenes. ${ }^{41-43}$ Subsequent studies by the groups of Ritter, Yu, and ourselves demonstrated the generality of these catalyst systems through the development of arene-limited nondirected $\mathrm{C}-\mathrm{H}$ cyanation reactions suitable for late-stage benzonitrile synthesis ${ }^{44-46}$ and very recently our group has developed an arene-limited nondirected $\mathrm{C}-\mathrm{H}$ alkynylation. ${ }^{47}$ These studies hint at the tremendous synthetic potential of a broadly applicable generation of aryl-palladium species through nondirected $\mathrm{C}\left(\mathrm{sp}^{2}\right)-\mathrm{H}$ activation. In order to fully exploit this potential, a detailed understanding of the catalytic systems and reaction mechanisms will be essential. Our catalyst systems, as well as the catalysts used by Ritter et al. for arene cyanation, are based on the use of two complementary ligands acting in concert: an $\mathrm{N}$-acyl amino acid derivative and an $\mathrm{N}$ heterocycle. Interestingly, while catalysts based on either one of these ligand types have been studied extensively, so far only few mechanistic details are available on this dual ligand catalysis approach. ${ }^{48-56}$

For this reason, we embarked on a combined experimental and theoretical study, using the $\mathrm{C}-\mathrm{H}$ olefination of arenes as model system. Herein we report the results of these studies that demonstrate the generality of dual ligand catalysis to address the reactivity and selectivity challenges encountered in nondirected Pd-catalyzed $\mathrm{C}-\mathrm{H}$ activation and are expected to serve a guiding role in future method development.

\section{RESULTS AND DISCUSSION}

Initial Studies. We began by focusing our attention on the key $\mathrm{C}-\mathrm{H}$ activation step. As documented in literature, four classes of mechanistic pathways are known for the metalmediated $\mathrm{C}-\mathrm{H}$ activation: concerted metalation/ deprotonation (CMD), ${ }^{50,51,57-65} \sigma$-bond metathesis, ${ }^{66-68}$ oxidative addition, ${ }^{69,70}$ and electrophilic metallation.66,71-74 In analogy to detailed mechanistic studies on Pd-catalysis using $N$-acetyl amino acids as single ligands, we began with the working hypothesis that the $\mathrm{C}-\mathrm{H}$ activation step would proceed via a CMD mechanism. Furthermore, Zhang and coworkers have demonstrated that for $\mathrm{Pd}^{\mathrm{II}}$-catalyzed Fujiwara-Moritani reactions the $\mathrm{C}-\mathrm{H}$ activation of the arene proceeds via a CMD mechanism and precedes the reaction of the catalyst with the olefin coupling partner. ${ }^{75}$ In order to learn more about the $\mathrm{C}-\mathrm{H}$ activation of arenes under dual ligand catalysis conditions through experimental techniques, it is essential that this step must be partially or fully rate-determining.

We started our mechanistic investigation by probing whether the $\mathrm{C}-\mathrm{H}$ activation contributes to the overall rate of the reaction using ortho-xylene as the model substrate (Scheme 2). Ortho-xylene was chosen because (a) only two regioisomers can form, (b) in contrast to toluene (1d) no di- olefination was observed, and (c) deuterated ortho-xylene (1b) is commercially available. Ligand $\mathbf{2}$ was used for kinetic studies instead of ligand $\mathbf{3}$ due to its commercial availability. This substitution is justified, since the two ligands perform almost identically in the model reaction (Scheme 2).

Scheme 2. The Dual Ligand-Enabled Nondirected C-H Olefination of Arenes as Model Reaction. ${ }^{a}$

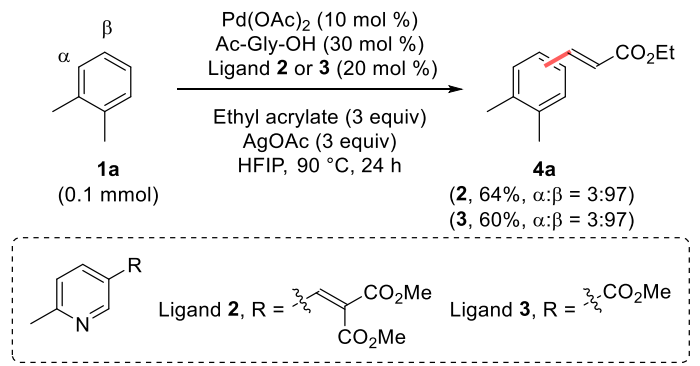

a Yields and regioselectivities determined by GC-FID. HFIP = 1,1,1,3,3,3-hexafluoroisopropanol.

Parallel and competition kinetic isotope effect (KIE) studies were conducted. The observed rates for the parallel experiments $\left(\mathrm{k}_{\mathrm{H}} / \mathrm{k}_{\mathrm{D}}=1.45\right.$, GC-FID, Scheme 3$)$ and the competition experiment $\left(\mathrm{k}_{\mathrm{H}} / \mathrm{k}_{\mathrm{D}}=2.00, \mathrm{NMR}\right.$, see Scheme S2 in the Supporting Information) between ortho-xylene and ortho-xylene- $\mathrm{d}_{10}$ both reveal a small primary kinetic isotope effect. Studies with deuterated ethyl acrylate showed no kinetic isotope effect on the rate of the reaction. These results indicated that the $\mathrm{C}-\mathrm{H}$ activation contributes to the overall reaction rate and thus, experimental methods could be used to gain knowledge about this step. The difference observed between the two experimental setups, as well as the comparably small magnitude of the observed KIE, implied that further steps in the catalytic cycle are likely to contribute to the rate of the reaction. ${ }^{76,77}$

\section{Scheme 3. Parallel Kinetic Isotope Effect Experiments.}

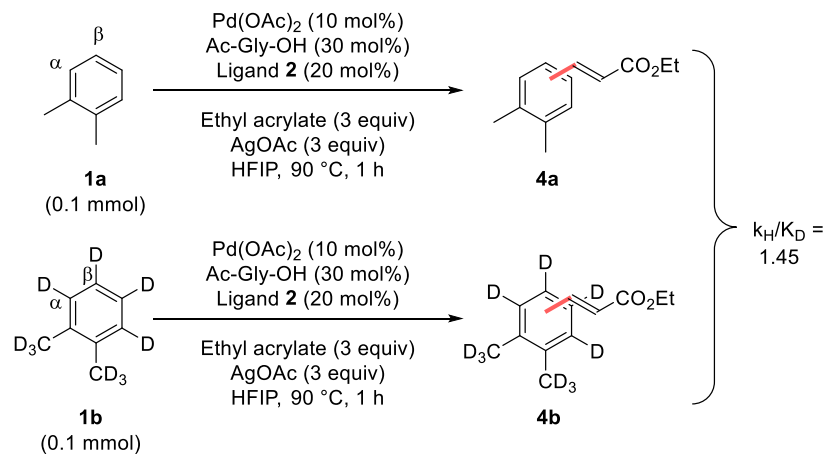

To obtain further information regarding the steps influencing the reaction rate, we proceeded to assess the kinetic orders in arene, olefin, and catalyst for the model system. The method of initial rates was used to determine the rate of product formation as a function of respective analyte concentration (Figure 1). 


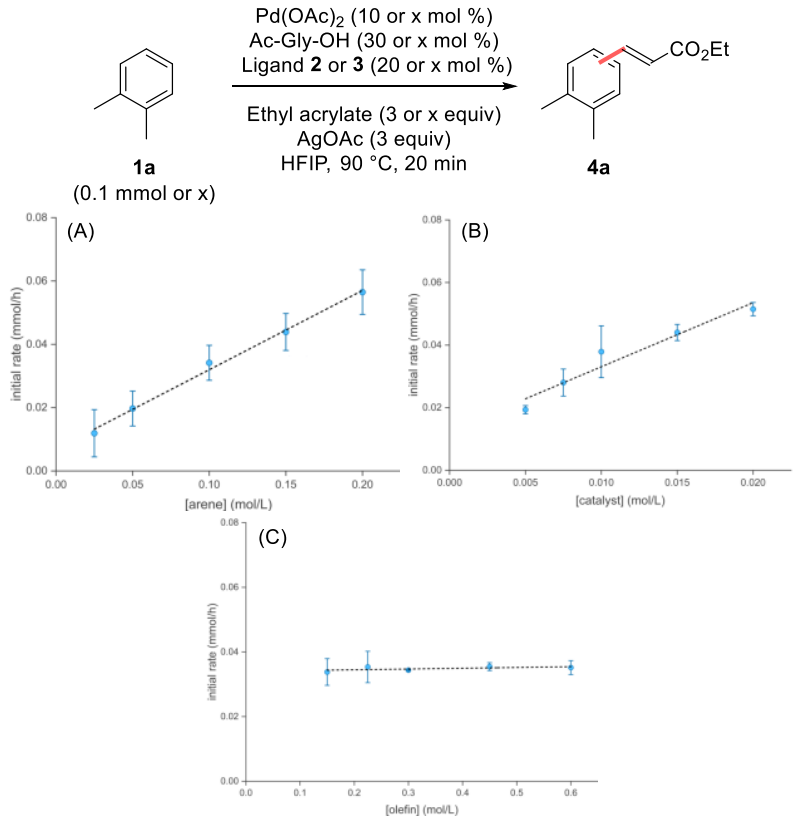

Figure 1. Plot of initial rate versus A [arene], B [catalyst] and C [olefin] following standard reaction conditions for kinetic experiments as in Scheme 2 quenched after 20 minutes (corresponding to conversions of $10 \%-20 \%$ ) and analyzed by GC-FID.

The reaction was found to be first order in ortho-xylene $(0.025-0.2 \mathrm{mmol})$. For the catalyst the amount of $\mathrm{Pd}(\mathrm{OAc})_{2}$ (5 - $20 \mathrm{~mol} \%$ ), Ac-Gly-OH (15 - $60 \mathrm{~mol} \%$ ), and ligand 2 (10 - $40 \mathrm{~mol} \%$ ) were varied in parallel keeping the ratio between the catalyst components constant. The analysis revealed a first-order dependence of the reaction on the catalyst concentration. The kinetic order in the olefin coupling partner ethyl acrylate $(0.15-0.60 \mathrm{mmol})$ was found to be zero, as expected for a component entering the catalytic cycle after the rate-limiting step. ${ }^{75}$

Stoichiometry Variation Experiments. Having confirmed that the catalyst concentration contributes to the reaction rate, we became interested in gathering further knowledge about the nature of the catalytically active species. Given that under the optimized reaction conditions an excess of both ligands is employed, we began with stoichiometry variation experiments, in order to determine the composition of the active species.

We thus studied the performance of catalysts generated upon combining different ratios of $\mathrm{Pd}(\mathrm{OAc})_{2}$, Ac-Gly-OH and the pyridine-derived ligand ( 2 or 3 ) in our model reaction (Table 1). Entry 1 shows that there is a significant "background reaction" catalyzed by palladium acetate in the absence of additional ligands. ${ }^{78,79}$ This can be rationalized considering that ortho-xylene (1a), a rather electron-rich arene, can undergo a comparably facile $\mathrm{C}-\mathrm{H}$ activation with the electrophilic $\mathrm{Pd}^{\mathrm{II}}$-catalyst. Adding (only) a pyridineligand to the system led to no improvement of the yield or regioselectivity (Entry 2). In contrast, the addition of Ac-Gly-OH improves the yield to $52 \%$ and at the same time increases the regioselectivity (Entry 3). Remarkably, when pyridine is added as a third component to the catalytic system, it induces an additional improvement of both yield and regioselectivity relative to the binary $\mathrm{Pd}: \mathrm{Ac}-\mathrm{Gly}-\mathrm{OH}$ catalyst (Entry 4). The change from a 1:1:1 ratio to the published reaction conditions (1:3:2) does not further improve the yield in the model reaction with ortho-xylene (Entry 5).

Table 1. Stoichiometry Variation Experiments with Ortho-Xylene (1a) as Starting Material.

\begin{tabular}{|c|c|c|c|}
\hline$\beta$ & \multicolumn{2}{|c|}{$\begin{array}{c}\mathrm{Pd}(\mathrm{OAc})_{2}(10 \mathrm{~mol} \%) \\
\text { Ac-Gly-OH }(0-30 \mathrm{~mol} \%) \\
\text { Ligand } 2(0-20 \mathrm{~mol} \%)\end{array}$} & \\
\hline $1 \mathbf{a}$ & \multicolumn{2}{|c|}{$\begin{array}{c}\text { Ethyl acrylate ( } 3 \text { equiv) } \\
\text { AgOAc ( } 3 \text { equiv) }\end{array}$} & $4 a$ \\
\hline Entry & $\begin{array}{c}\text { Ratio } \\
\text { Pd:Ac-Gly-OH:Pyr }\end{array}$ & Yield (\%) & $\alpha: \beta$ \\
\hline 1 & 1:0:0 & 42 & $18: 82$ \\
\hline 2 & 1:0:1 & 39 & $17: 83$ \\
\hline 3 & $1: 1: 0$ & 52 & $10: 90$ \\
\hline 4 & 1:1:1 & 62 & 4:96 \\
\hline 5 & $1: 3: 2$ & 60 & $3: 97$ \\
\hline
\end{tabular}

The reactions in this table were conducted on a $0.1 \mathrm{mmol}$ scale and yields determined by GC-FID using 1,3,5trimethoxybenzene as internal standard.

The results in Table 1 allow for several conclusions. On the one hand, they show that a higher yielding and more selective catalyst is formed as soon as all three catalyst components are present in at least a 1:1:1 ratio, while no second equivalent of either ligand is required for the optimal catalyst performance. On the other hand, the substantial product formation observed for $\mathrm{Pd}(\mathrm{OAc})_{2}$ alone and the binary systems implies that the results obtained with this model system may correspond to the superimposition of the catalysis by several active species present in the reaction mixture, which could in principle lead to erroneous conclusions when comparing different reaction conditions. Thus, to eliminate this potential source of error, a second model system was required, in which only the catalyst containing both ligands would show considerable catalytic activity. We reasoned that this might be the case for a substantially more electron-poor substrate such as HFIP benzoate (1c).

We were pleased to find that indeed the reaction with this substrate does not proceed until $\mathrm{Pd}(\mathrm{OAc})_{2}$ and both ligands are present (Entries 1-4, Table 2). Furthermore, with this substrate, an improved reaction outcome was observed under the previously optimized reaction conditions (Entry 5). At this point, several explanations remained possible for the superiority of the 1:3:2 over the 1:1:1 stoichiometry. While the identical selectivities observed with both model reactions imply that the catalytically active species remains the same, the excess ligands provided could either affect the catalyst speciation, thereby increasing the concentration of the active species, or serve to protect the catalyst from decomposition at another stage of the catalytic cycle. 
Table 2. Stoichiometry Variation Experiments with HFIP Benzoate (1c) as Starting Material.

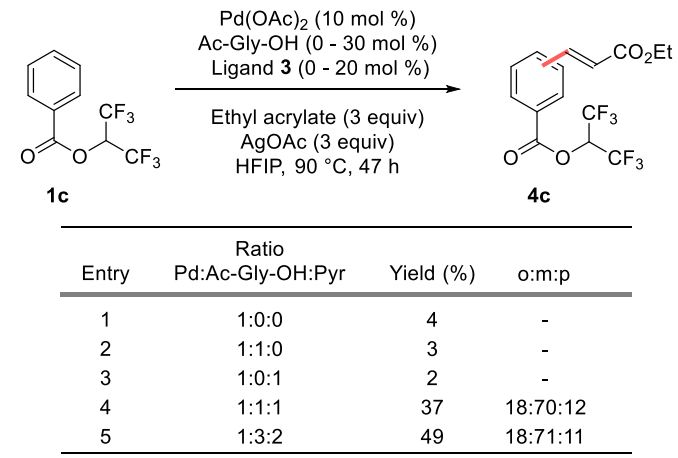

The reactions in this table were conducted on a $0.1 \mathrm{mmol}$ scale and yields determined by GC-FID using 1,3,5trimethoxybenzene as internal standard.

In order to differentiate between these scenarios, we proceeded to study the initial rates of reactions conducted with varied catalyst compositions (Scheme 4). For orthoxylene (1a) the initial rate is highest without any pyridinederived ligand and decreases exponentially the more pyridine is added (Scheme 4, A). For Ac-Gly-OH a maximum in catalytic activity is reached in the range between 0.1 and 0.2 equivalents (Scheme 4, B), the addition of further ligand again leading to a decreased catalyst activity. These results show that for substrate 1a the most active catalyst is formed in the absence of a pyridine-ligand. However, while less active, a substantially more selective and longer-lived catalyst involving both ligand types can be formed when a pyridine ligand is present ( $c f$. Table 1 ). The slope observed in Scheme 4A can thus be interpreted as the continuous transition between differently active catalytic species.

As expected, based on the results in Table 2, no catalytic activity for the olefination of HFIP benzoate (1c) was observed in absence of either ligand. The initial rate increased sharply to a maximum at around 0.15 equivalents for both ligands, the addition of further equivalents leading to decreased activities (Scheme 4, C and D). These results show that for more challenging to activate substrates such
Scheme 4. Initial Rate Experiments with Ortho-Xylene (1a, left) and HFIP Benzoate (1c, right) as Starting Materials.
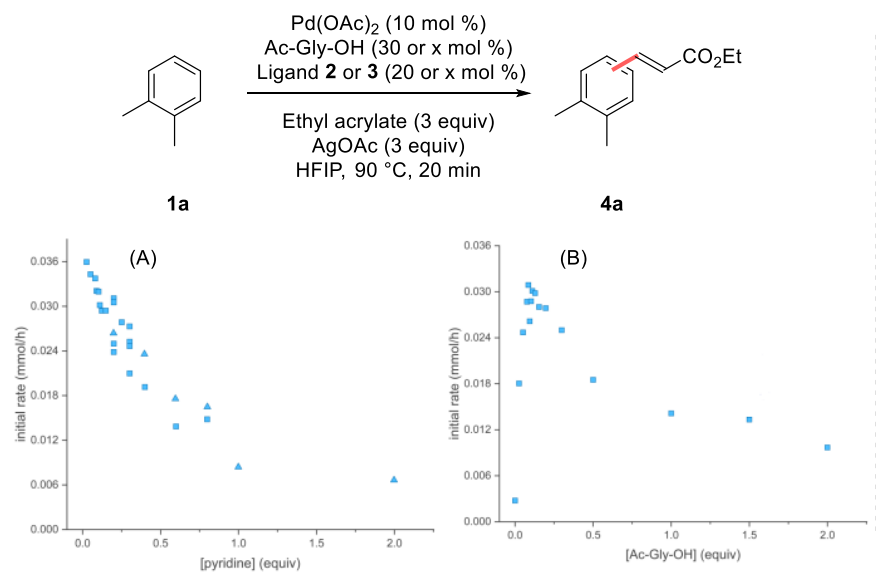

as 1c, a 1:1:1 species leads to superior results not only due to an increased catalyst lifetime, but due to a higher catalytic activity. Additionally, the detrimental effect of adding larger quantities of either ligand can be interpreted as the result of a shift in catalyst speciation away from the desired 1:1:1 complex. Under the optimized reaction conditions, where a 1:3:2 ratio between the components is employed, these species may also serve as resting states, thereby contributing to the stability of the catalytic system. ${ }^{80}$ In this context it should be noted that the formation of a catalytically inactive species with two pyridine ligands per Pd has been documented for different $\mathrm{C}-\mathrm{H}$ activation reactions with $\mathrm{Pd}(\mathrm{OAc})_{2}$ and other catalysts. ${ }^{53,54,81-83}$ The introduction of bulky substituents in the ortho-positions of the pyridine can cause a steric clash between the two pyridine ligands and thus shift the equilibrium towards a catalytically active mono pyridine complex. ${ }^{54,75}$ Similarly, this equilibrium can be influenced by electron-withdrawing groups on the pyridine-ligand, which weaken the $\mathrm{Pd}-\mathrm{N}$ bond. ${ }^{53,81,84}$

Importantly, although the overall rates of product formation are shown in Scheme 4, the same influences of the ligands on the regioselectivity as in Tables 1 and 2 were observed in the kinetic studies, once again showing that when both ligands are present in the reaction mixture, the product formation occurs through a distinct catalytic species containing all catalyst components.

Nuclearity of the Active Species. While the data obtained so far confirmed the stoichiometry of the catalytically active species, its nuclearity remained to be investigated. It is in generally well documented that $\mathrm{Pd}^{\mathrm{II}}$ complexes can adopt a variety of forms, such as monomers, dimers, trimers, and oligomers. The question of nuclearity becomes particularly relevant when $N$-acetyl amino acids are used as ligands, since they can interact with palladium through a number of known binding modes, the most common of which are the bidentate di-anionic $\left(\kappa^{2}-(N, O)^{-2}\right)$, the bidentate mono-anionic $\left(\kappa^{2}-(N, O)^{-1}\right)$, and the bridging mono-anionic $\left(\mu-(O, O)^{-1}\right)$ coordination. ${ }^{85,86}$

The amount of pyridine-derived ligand 2 (blue squares), 3 (blue triangles) or Ac-Gly-OH was varied. The reactions in this scheme were conducted on a $0.1 \mathrm{mmol}$ scale and yields determined by GC-FID using 1,3,5-trimethoxybenzene as internal standard. 
The potential role of dinuclear Pd-species in Pd-pyridine, as well as $\mathrm{Pd}-\mathrm{N}$-acetyl amino acid systems, has been investigated intensively with both experimental and computational methods.87-92 Depending on the system studied, dinuclear or higher-order complexes have been found both as on-cycle and as off-cycle species. ${ }^{92}$ Importantly, the observation that the reaction is first order with respect to palladium implies that a possible equilibrium between mononuclear and higher order species should be shifted strongly to either of the two sides, since the concentration of catalyst would otherwise influence this equilibrium leading to broken kinetic orders. $^{92}$ Thus, the detection of either mononuclear or higher order species under conditions sufficiently similar to those used in catalysis would in this particular case allow us to draw conclusions regarding the nuclearity of the catalytically active species.

HRMS Studies. The mass spectra obtained from a 1:3:2 mixture of $\mathrm{Pd}(\mathrm{OAc})_{2}$ :Ac-Gly-OH:ligand 2 in HFIP show ions corresponding to mononuclear complexes with 1:0:2, 1:1:1, 1:0:1 and 1:1:2 stoichiometries (Figure $2 \mathrm{~A}$ ). No signals were detected that could be attributed to aggregates or higher order species. The peak assignment was confirmed by matching with the theoretical isotope patterns (see Figure 2, B and C; Figure F8-F13 in the Supporting Information).

While it should be noted that the observation of a complex in the gas phase does not necessarily coincide with relevance for catalysis, ${ }^{93}$ these data imply mononuclear species to dominate the equilibrium in HFIP as solvent. Furthermore, the detection of a 1:1:2 species agrees well with the proposed existence of a catalytically inactive resting state involving an additional equivalent of ligand. When an analogous measurement was conducted using a

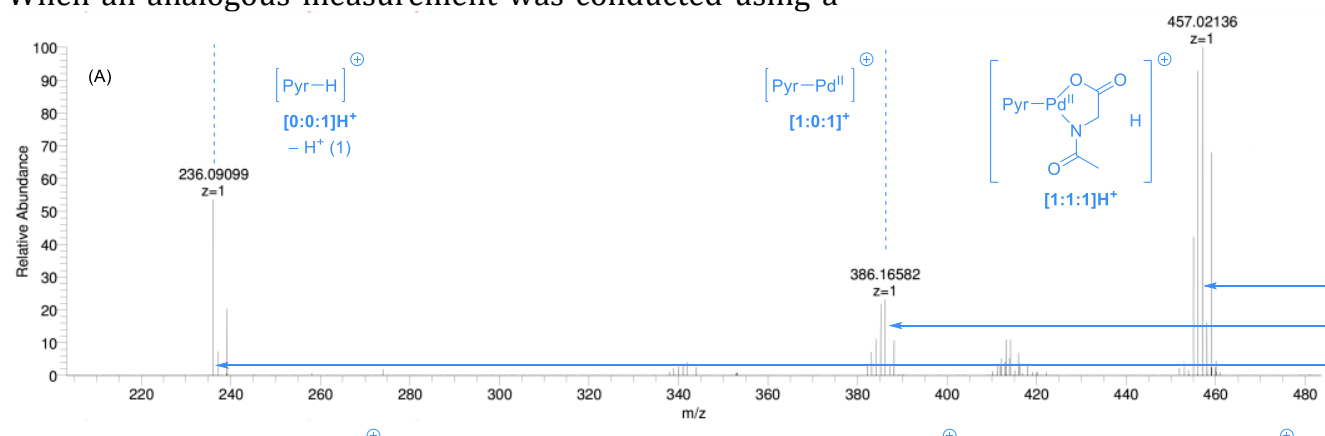

$1: 20: 2$ ratio of the catalyst components, further mononuclear complexes with $1: 2: 0,1: 2: 1$, and $1: 2: 2$ stoichiometries were observed. These data confirm that an excess of either ligand 2 or Ac-Gly-OH is capable of shifting speciation away from the catalytically active 1:1:1 complex. However, the fact that the species containing two equivalents of ligand $\mathbf{2}$ was observable with the catalytically relevant ratio of ligands, while a large excess of Ac-Gly-OH was required to detect the corresponding species, implies that the $1: 1: 2$ complex is more likely to serve as the resting state (Scheme 5).

\section{Scheme 5. Proposed Active Species and Resting State.}

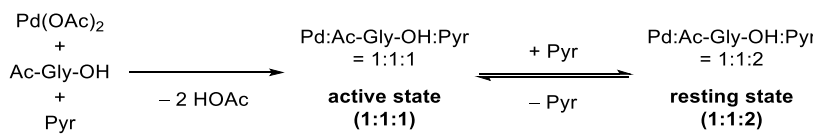

To further elucidate the relation between the observed species, collision induced dissociation (CID) experiments were performed. The peak at $m / z 692$ assigned to the 1:1:2 complex was mass-selected and after analysis by the MS/MS method fragments corresponding to 1:0:2, 1:1:1, 1:0:1 and 0:0:1 stoichiometries could be observed (Figure 2). We furthermore observed a signal that can be explained by the decomposition of Ac-Gly-OH, which loses a $\mathrm{OCCH}_{2}$ fragment while remaining bidentately coordinated, a pathway commonly observed for $\mathrm{N}$-acetylated amino acids. ${ }^{50}$ These results show that the 1:1:2 complex proposed to be the resting state in our catalytic system readily dissociates one pyridine ligand to give the 1:1:1 complex identified as the active species.

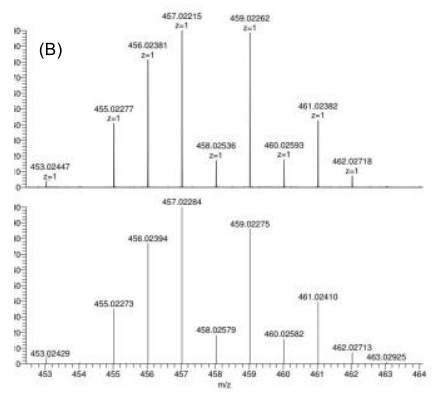

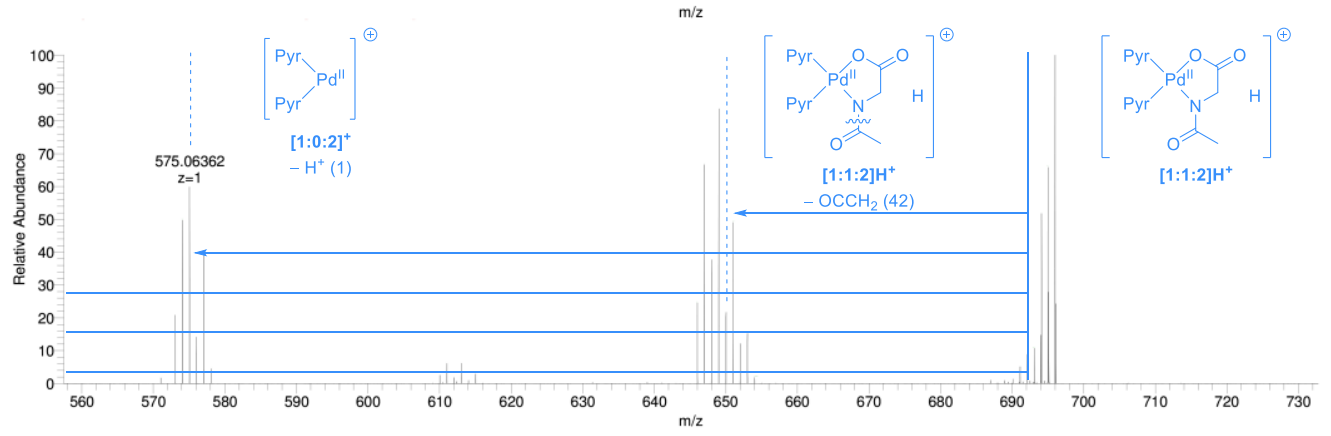

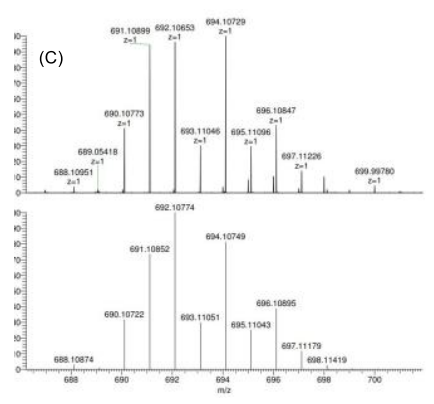

Figure 2: (A) CID Fragmentation analysis of protonated 1:1:2 complex of Pd:Ac-Gly-OH:ligand 2 in HFIP (collision gas: helium, $\mathrm{U}_{\text {trap }}$ $=15 \mathrm{~V}$ ). Experimental (top) and theoretical (bottom) isotope patterns for the proposed active species [1:1:1] $\mathrm{H}^{+}(\mathrm{B})$ and resting state $[1: 1: 2] \mathrm{H}^{+}(\mathrm{C})$. Ions generated from a millimolar HFIP solution of 1:3:2 (A) or 1:1:2 (B and C) stoichiometry (Pd(OAc)2:Ac-Gly$\mathrm{OH}$ :ligand 2). 
NMR Studies. To further investigate the nature of the active species in solution NMR studies were conducted. Considering that HFIP proved to be crucial for the performance of the catalyst system meaningful results could not be expected from experiments conducted in another solvent. Since deuterated HFIP is not commercially available all NMR experiments were conducted in regular HFIP with acetone-d 6 in a coaxial tube for external locking.

Diffusion ordered NMR spectroscopy (DOSY) has emerged as a powerful tool to determine the molecular weight of complexes in solution since the diffusion constant (D) depends on the size and is proportional to the MW using the relationship $\log \mathrm{MW} \propto \log$ D. ${ }^{81,94,95}$

While ${ }^{1} \mathrm{H}$-DOSY has been used extensively for absolute diffusion information to estimate the size of molecules and aggregates, the catalyst shown in Scheme 2 proved to be too complex for a determination of diffusion constants (D) by ${ }^{1} \mathrm{H}-\mathrm{NMR}$. We envisaged that by applying heteronuclear ${ }^{19} \mathrm{~F}$ DOSY with a ${ }^{19} \mathrm{~F}$-labeled pyridine ligand would allow us to analyze the different catalytic species in solution separately due to the large chemical shift dispersion of ${ }^{19} \mathrm{~F}$ compared to ${ }^{1} \mathrm{H}$ and the reduced overall number of peaks. ${ }^{19} \mathrm{~F}$-DOSY has been applied to determine monomer/dimer equilibria and molecular weights (MW) of complexes in solution. ${ }^{96,97}$

To avoid hydrogen bonding to the solvent, six fluorinated molecules without Lewis basic functional groups were selected as internal standards. In order to introduce fluorine into the catalyst, 3,5-difluoropyridine was chosen to replace ligands 2 and 3 . While not delivering optimal results, the use of this ligand was found to result in catalytic activity, thus implying that meaningful data could be obtained through this replacement.

The ${ }^{19} \mathrm{~F}-\mathrm{NMR}$ of a $1: 1: 2$ Pd(OAc) 2 :Ac-Gly-OH:3,5difluoropyridine mixture in HFIP gave a complex but wellresolved spectrum, showing the presence of several pyridine-containing complexes. The MWs determined by internal standard reference ${ }^{19} \mathrm{~F}$-DOSY are slightly too high for simple mononuclear complexes, but at the same time drastically too low for analogous dinuclear species (Scheme 6). We hypothesized that the overestimation of the MW could be explained by hydrogen bonding between the complexes and HFIP. Analogous hydrogen bonding has been observed numerous times, for example between HFIP and amino acids. ${ }^{98-101}$ In accordance with this proposal, the MW calculated for mononuclear complexes diffusing alongside one molecule of HFIP (1:1:2·HFIP) lies well within the measured range of diffusion constants.

To further validate the hypothesis of hydrogen bonding between HFIP and the catalyst, three model compounds with and without hydrogen bond acceptors were analyzed. While the MWs measured for molecules without suitable Lewis basic functional groups were determined accurately, the mass measured for 4-fluoro- $N, N$-dimethylbenzamide corresponds to a 1:1 adduct with HFIP).

In agreement with our findings from mass spectrometry, the above ${ }^{19} \mathrm{~F}$-DOSY results indicate that mononuclear complexes are the predominant species formed from the three catalyst components in HFIP at room temperature.
Scheme 6. ${ }^{19}$ F-DOSY NMR (600 MHz, HFIP/Acetone-d 6 in Coaxial Tube, $26^{\circ} \mathrm{C}$ ) Log-Log Plot of Molecular Weight (MW) as a Function of Mobility (D).

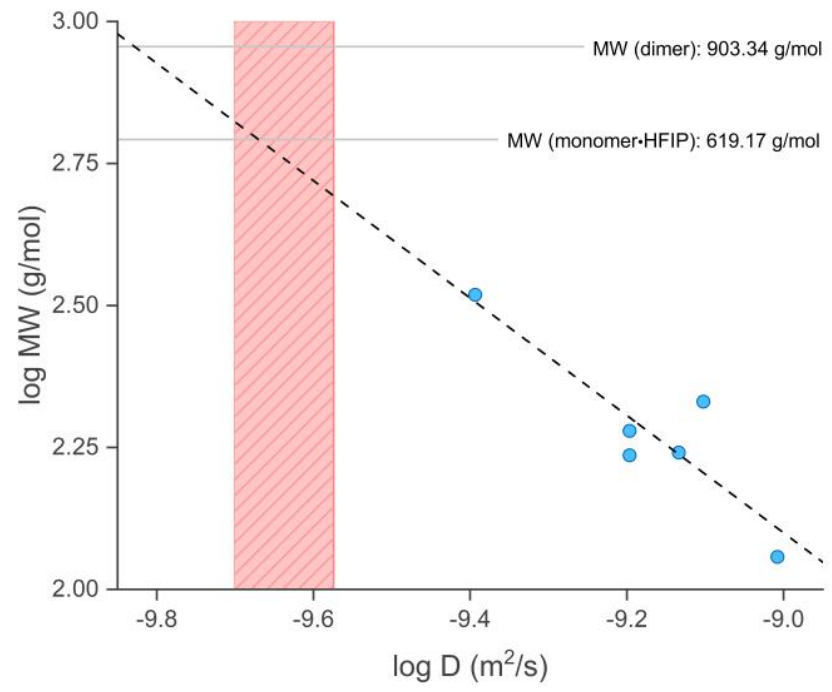

Standards (blue circles) used are 1,3-difluorobenzene, 2fluorobiphenyl, $\quad 4,4$ '-difluorobiphenyl, 1,3 bis(trifluoromethyl)benzene, (3,3,3-trifluoropropyl)benzene, and triethoxy(perfluorophenyl)silane. The range of log D values for the palladium complexes is shown as red area.

The NMR results thus corroborate to identification of these mononuclear complexes as the catalytically active species.

Proposed Mechanism of the C-H Activation Step. Based on the results discussed above, we conclude that the dual ligand catalyzed $\mathrm{C}-\mathrm{H}$ activation proceeds through mononuclear species. The $\mathrm{C}-\mathrm{H}$ activation step is preceded by an equilibrium between a 1:1:2 (Pd:Ac-Gly-OH:pyridine) resting state 5 and the 1:1:1 (Pd:Ac-Gly-OH:pyridine) active species 6 (scheme 7). This active species subsequently engages in a rate-limiting $\mathrm{C}-\mathrm{H}$ activation, the activation barrier being defined by the energy difference between the resting state and the transition state of the $\mathrm{C}-\mathrm{H}$ activation. In analogy to literature reports we expect the reaction to continue with a ligand exchange, bringing the olefin into the coordination sphere of the Ar-Pd species. ${ }^{50,51,75,102}$ Given that we observe a zero order in the olefin, these steps must, as observed in previous studies, proceed through activation barriers lower than that of the $\mathrm{C}-\mathrm{H}$ activation step and thus do not contribute to the rate or selectivity of the overall process. ${ }^{50,102}$ In order to obtain further insights into the reactivity and selectivity determining transition state, we proceeded to study the $\mathrm{C}-\mathrm{H}$ activation step computationally.

DFT Studies. We started the theoretical investigation by determining the free energy of intermediates and transition states of a model system based on unsubstituted pyridine with Ac-Gly-OH and benzene as the substrate. Computational studies were performed using the TURBOMOLE program. ${ }^{103}$ Structures were optimized with the hybrid functional PBE0-D3 and electronic energies calculated with the hybrid meta GGA functional PW6B95(D3). ${ }^{104-106}$ 
Scheme 7. Proposed Formation of the Resting State 5 and Active State 6.

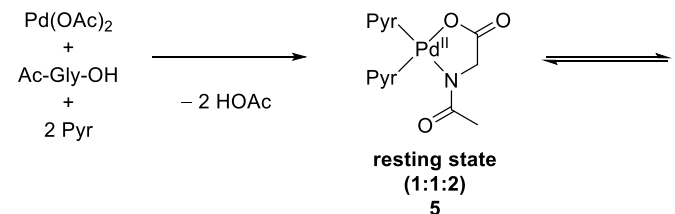

All energies and free energy corrections are given in Table T14 of the Supporting Information including implicit solvation in HFIP. The resting state $\mathbf{5 c}$ with a stoichiometry of 1:1:2 (Pd:Ac-Gly-OH:pyridine) is significantly more stable than the active state $\mathbf{6} \mathbf{c}$ with one pyridine dissociated (see Figure F20 in the supporting information for the energy diagram of 5c-9c). The active state complex $\mathbf{8}$ is stabilized by an interaction between palladium and the amide carbonyl group of the $N$-acetyl amino acid ligand. The free energy of dissociation is $+12.5 \mathrm{kcal} / \mathrm{mol}$. The association of benzene to form the pre-reactive complex 8c is slightly endergonic $(+2.2 \mathrm{kcal} / \mathrm{mol})$. Formation of the CMD-transition state $9 c$ requires an additional free energy of activation of $+9.7 \mathrm{kcal} / \mathrm{mol}$. The total energy barrier for the $\mathrm{C}-\mathrm{H}$ activation of benzene thus amounts to $\Delta \mathrm{G}^{\ddagger} 298(\mathbf{5 c} \rightarrow \mathbf{9 c})=24.4 \mathrm{kcal} / \mathrm{mol}$.

When we replaced pyridine with methyl 6methylnicotinate (3) we observed that the energy of the resting state $5 a(12.6 \mathrm{kcal} / \mathrm{mol})$ is almost identical to that of $\mathbf{5 c}$ (Figure 3). In comparison, the association of benzene to the active state complex 6 a requires more energy $(+7.4 \mathrm{kcal} / \mathrm{mol})$, while the free energy of the transition state 9a is lower $(+11.3 \mathrm{kcal} / \mathrm{mol})$ than with pyridine. The free energy barrier for the reaction from $\mathbf{5 a}$ to $\mathbf{9 a}$ is slightly lower with a total of $\Delta \mathrm{G}^{\ddagger}{ }_{298}(\mathbf{5 a} \rightarrow \mathbf{9 a})=23.9 \mathrm{kcal} / \mathrm{mol}$. The
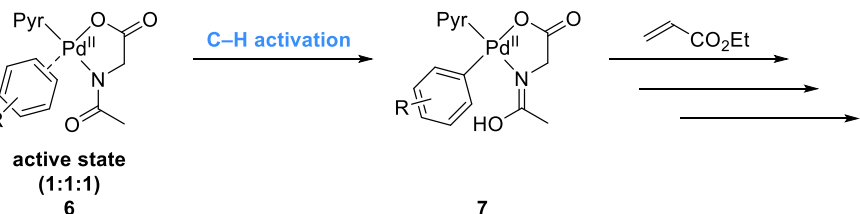

formation of the Pd-aryl organometal species $7 \mathbf{a}$ is exergonic in relation to the pre-reactive complex $\mathbf{6 a}$.

To investigate the kinetic control of the regioselectivity in the reaction of a substituted arene we used $t$-butylbenzene as the model substrate. In the $\mathrm{C}-\mathrm{H}$ activation catalyzed by catalyst $\mathbf{6 a}$ the association of the substituted arene to form the pre reactive complex $\mathbf{8 b}$ requires slightly less energy $(+6.5 \mathrm{kcal} / \mathrm{mol})$ than the association of benzene. The free energies of the transition states $\mathbf{9 b}$ are different depending on which position of the ring undergoes $\mathrm{C}-\mathrm{H}$ activation. The transition states leading to the meta-product (9b-meta, $10.2 \mathrm{kcal} / \mathrm{mol}$ ) and para-product (9b-para, $10.4 \mathrm{kcal} / \mathrm{mol}$ ) were identified. Both are very similar in energy and lower than the respective free energy of 9a. However, the transition state $\mathbf{9 b}$-ortho is significantly higher in energy with $12.6 \mathrm{kcal} / \mathrm{mol}$ due to steric clash of the $t$-butyl group with the catalyst. This supports our experimentally found selectivity preference for $t$-butylbenzene with a regioselectivity of $\mathrm{m}: \mathrm{p}=58: 42$ using ligand 2 with no orthoproduct formation. ${ }^{41}$ The total free energy barriers of the $\mathrm{C}$ $\mathrm{H}$ activation of $t$-butylbenzene amount to $\Delta \mathrm{G}^{\ddagger} 298(\mathbf{5 b} \rightarrow \mathbf{9 b})=$ $22.8 \mathrm{kcal} / \mathrm{mol}$ (meta), $23.0 \mathrm{kcal} / \mathrm{mol}$ (para) and $25.2 \mathrm{kcal} / \mathrm{mol}$ (ortho). The lower barrier for the formation of 9b-meta and 9b-para compared to $9 \mathbf{c}$ is in good agreement with the experimentally observed activating effect exerted by donor substituents on the substrate.

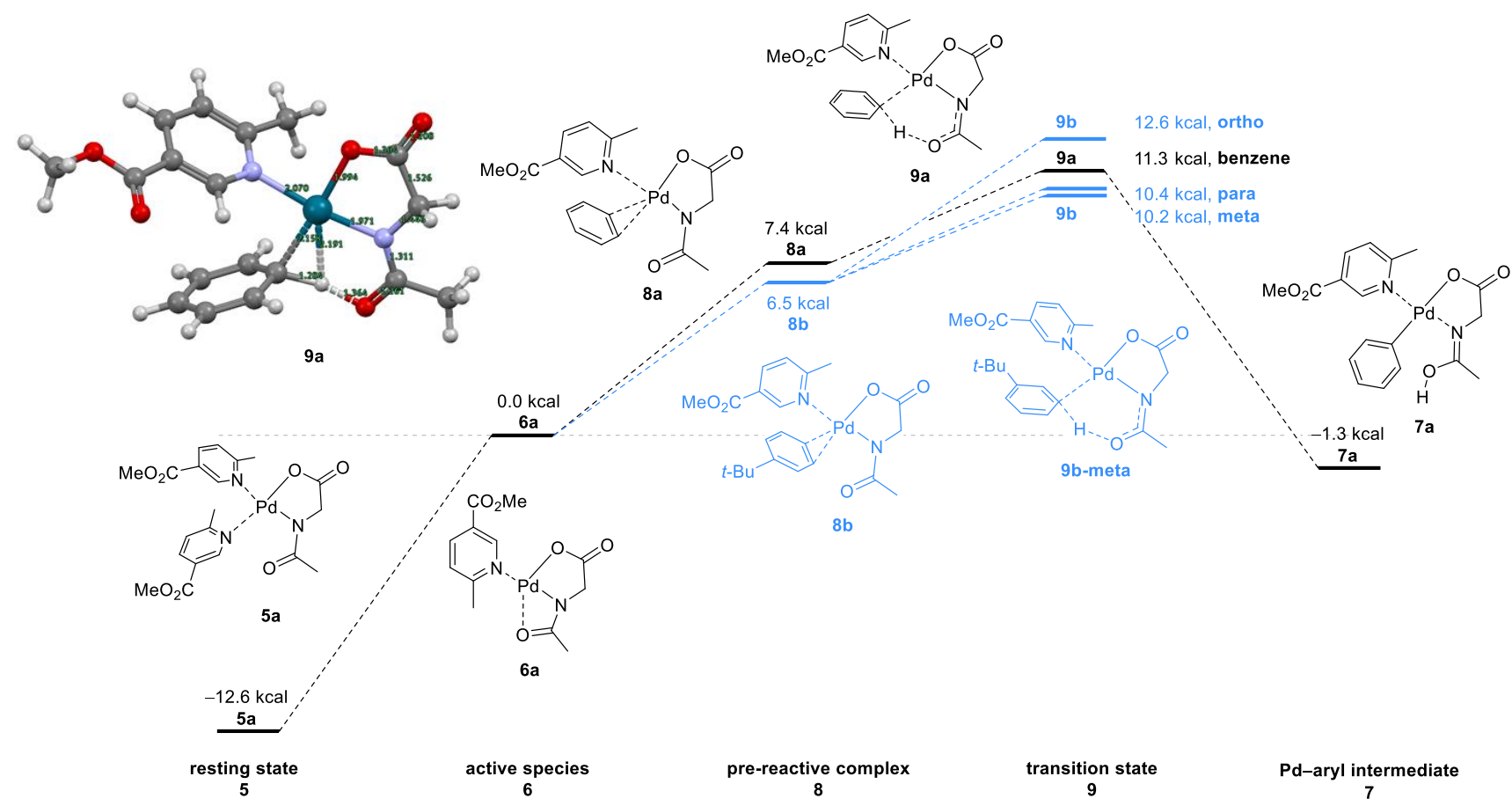

Figure 3: Reaction coordinate (free energy profile, $\Delta \mathrm{G}_{298}(\mathrm{sol}) \mathrm{kcal} / \mathrm{mol}$ ) for the arene-limited nondirected $\mathrm{C}-\mathrm{H}$ activation of arenes with palladium. Energies ( $\mathrm{kcal} / \mathrm{mol}$ ) are given relative to the active state $\mathbf{6 a}$. 
The energies of the transition states 9 support our assessment that the $\mathrm{C}-\mathrm{H}$ activation step is partially turnover limiting. The reaction coordinate predicts a first order in arene and a small primary KIE due to the preceding equilibrium contributing to the total energy barrier and the thermal free energy profile is consistent with the results of our kinetic analysis

Proposed Catalytic Cycle. Based on the kinetic investigation, spectroscopic and spectrometric data, and the theoretical analysis presented above, as well as analogies to related literature reports, we propose the catalytic cycle shown in Figure 3 . Accordingly, the $\mathrm{C}-\mathrm{H}$ activation of the arene by the active species $\mathbf{6}$ is preceded by an equilibrium with the resting state $\mathbf{5}$. The arene coordinates to palladium to form the pre-reactive complex 8. The regio-determining $\mathrm{C}-\mathrm{H}$ activation proceeds through a concerted 6-membered transition state to form the Ar-Pd intermediate $\mathbf{7}$ and is the last part of the rate-limiting sequence ranging from resting state 5 to transition state $\mathbf{9}$. In congruence with prior mechanistic investigation of the Fujiwara-Moritani reaction, we expect the next step to be a ligand exchange that introduces the olefin to the coordination sphere of palladium (10). ${ }^{50,51,75}$

In analogy to the intensively studied mechanisms of the Fujiwara-Moritani reaction and the Mizoroki-Heck reaction, we propose the reaction to further proceed via a carbometallation giving intermediate $\mathbf{1 1}$ and a subsequent $\beta$-H-elimination forming complex 12.

Scheme 8. Proposed Catalytic Cycle.

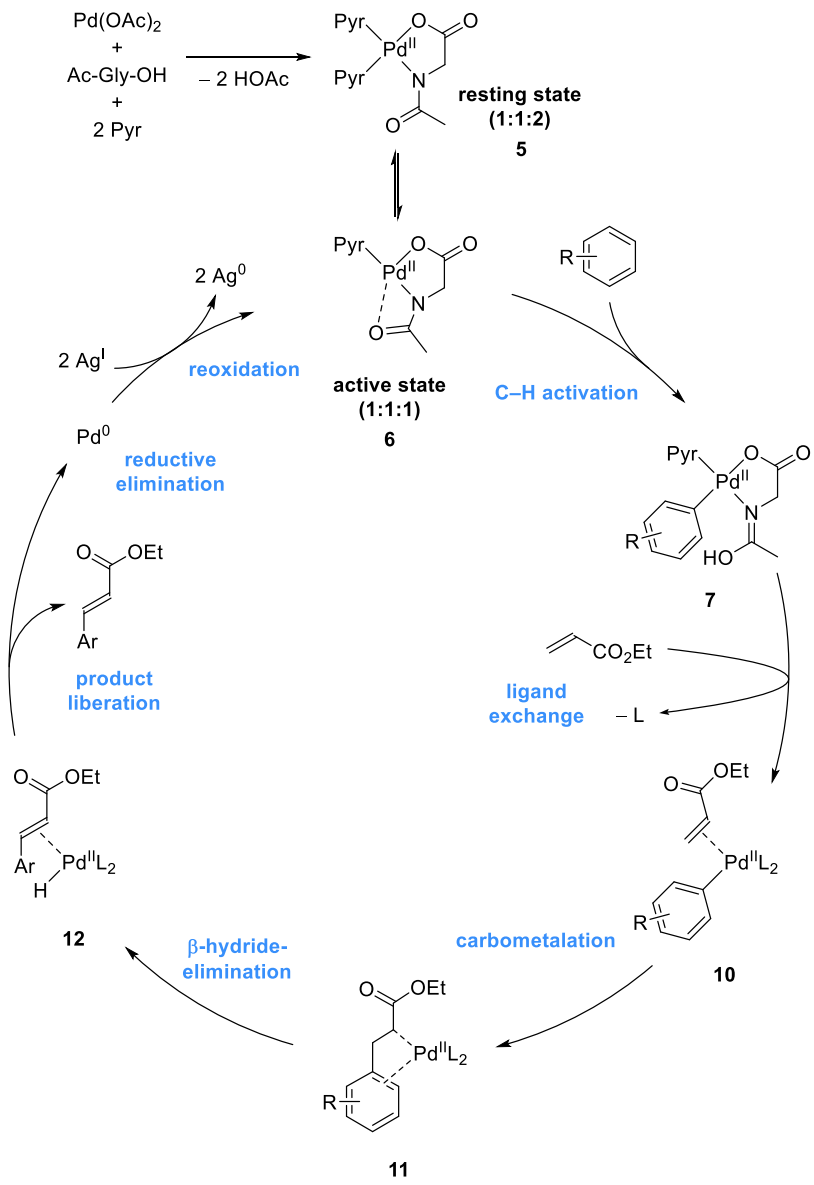

From here, the product can be liberated by ligand exchange, which concomitantly forms a $\mathrm{Pd}^{\mathrm{II}}$-hydridespecies that undergoes reductive elimination to a $\mathrm{Pd}^{0}$ intermediate. Finally, the catalytic cycle is closed through a re-oxidation to $\mathrm{Pd}^{\mathrm{II}}$ by the silver salt used as terminal oxidant. The involvement of the silver salt after the product forming step of the catalytic cycle was probed experimentally: In a reaction without silver salt but with a stoichiometric amount of $\mathrm{Pd}(\mathrm{OAc})_{2}, \mathrm{Ac}-\mathrm{Gly}-\mathrm{OH}$, and ligand 3, the HFIP-benzoate 1c could be functionalized in $39 \%$ yield. ${ }^{107}$ The regioselectivity was found to be very similar to the one observed under catalytic conditions (o:m:p = 20:59:21).

Our investigations have revealed that both ligands play an essential role at various stages of the catalytic cycle. The electron-poor nature of the pyridine leads to a relatively weak N-Pd bond, in turn allowing for formation of the active state $\mathbf{6}$ from the resting state $\mathbf{5 .}^{53,75,81}$ At the same time the formation of the resting state likely protects the catalyst against decomposition.

The amide carbonyl group of Ac-Gly-OH facilitates the C$\mathrm{H}$ activation step by acting as internal base. ${ }^{48-50}$ The bidentate nature of this ligand additionally brings the pyridine into the cis position relative to the substrate, which supports the observed steric control of the regioselectivity.

\section{CONCLUSIONS}

We report a combined experimental and computational investigation of the arene-limited nondirected $\mathrm{C}-\mathrm{H}$ olefination of arenes by dual ligand-enabled palladium catalysis. Using techniques including kinetic measurements, (CID-)MS, (DOSY-)NMR, and DFT studies has allowed us to propose a catalytic cycle that readily explains the role of both ligands used to enable remarkably high catalytic activities and regioselectivities that complement other existing technologies.

Dual ligand catalysis has only recently been recognized as a highly useful tool to achieve the nondirected $\mathrm{C}-\mathrm{H}$ activation of arenes with the arene as the limiting reagent. The potential of such catalysts to enable valuable methods for late-stage modification is reflected by a rapidly increasing number of applications of dual ligand catalysis. We expect that the insights into the underlying mechanism presented herein will prove highly useful in the rational development of novel catalysts and synthetic methods.

\section{ASSOCIATED CONTENT}

The Supporting Information is available free of charge via the Internet at http://pubs.acs.org.

Full experimental details for data acquisition, supplementary experiments and additional discussion (PDF)

\section{AUTHOR INFORMATION}

\section{Corresponding Authors}

*cml@uni-muenster.de

*mvangemmeren@uni-muenster.de 


\section{Notes}

The authors declare no competing financial interest.

\section{ACKNOWLEDGMENT}

We thank the members of our NMR and MS departments for their excellent service. We also thank Dr. M. Letzel for the collection of mass spectrometry data. We gratefully acknowledge the financial support from the Max Planck Society (Otto Hahn Award to M.v.G.), the FCI (Liebig Fellowship to M.v.G.), and the WWU Münster. We thank Prof. F. Glorius for his generous support.

\section{REFERENCES}

(1) McMurray, L.; O’Hara, F.; Gaunt, M. J. Recent developments in natural product synthesis using metalcatalysed C-H bond functionalisation. Chem. Soc. Rev. 2011, 40, 1885-1898.

(2) Yamaguchi, J.; Yamaguchi, A. D.; Itami, K. C-H bond functionalization: emerging synthetic tools for natural products and pharmaceuticals. Angew. Chem. Int. Ed. 2012, 51, 8960-9009.

(3) Wencel-Delord, J.; Glorius, F. C-H bond activation enables the rapid construction and late-stage diversification of functional molecules. Nature chemistry 2013, 5, 369-375.

(4) Hartwig, J. F. Evolution of C-H Bond Functionalization from Methane to Methodology. J. Am. Chem. Soc. 2016, 138, $2-24$.

(5) Fox, J. C.; Gilligan, R. E.; Pitts, A. K.; Bennett, H. R.; Gaunt, M. J. The total synthesis of K-252c (staurosporinone) via a sequential C-H functionalisation strategy. Chem. Sci. 2016, 7, 2706-2710.

(6) Cernak, T.; Dykstra, K. D.; Tyagarajan, S.; Vachal, P.; Krska, S. W. The medicinal chemist's toolbox for late stage functionalization of drug-like molecules. Chem. Soc. Rev. 2016, 45, 546-576.

(7) Blakemore, D. C.; Castro, L.; Churcher, I.; Rees, D. C.; Thomas, A. W.; Wilson, D. M.; Wood, A. Organic synthesis provides opportunities to transform drug discovery. Nature chemistry 2018, 10, 383-394.

(8) Taylor, R. D.; MacCoss, M.; Lawson, A. D. G. Rings in drugs. J. Med. Chem. 2014, 57, 5845-5859.

(9) Whisler, M. C.; MacNeil, S.; Snieckus, V.; Beak, P. Beyond thermodynamic acidity: a perspective on the complexinduced proximity effect (CIPE) in deprotonation reactions. Angew. Chem. Int. Ed. 2004, 43, 2206-2225.

(10) Ackermann, L. Carboxylate-assisted transition-metalcatalyzed $\mathrm{C}-\mathrm{H}$ bond functionalizations: mechanism and scope. Chem. Rev. 2011, 111, 1315-1345.

(11) Brückl, T.; Baxter, R. D.; Ishihara, Y.; Baran, P. S. Innate and guided C-H functionalization logic. Acc. Chem. Res. 2012, 45, 826-839.

(12) Chen, X.; Engle, K. M.; Wang, D.-H.; Yu, J.-Q. Palladium(II)-catalyzed $\mathrm{C}-\mathrm{H}$ activation/C-C cross-coupling reactions: versatility and practicality. Angew. Chem. Int. Ed. 2009, 48, 5094-5115.

(13) Chen, Z.; Wang, B.; Zhang, J.; Yu, W.; Liu, Z.; Zhang, Y. Transition metal-catalyzed $\mathrm{C}-\mathrm{H}$ bond functionalizations by the use of diverse directing groups. Org. Chem. Front. 2015, 2, 1107-1295.

(14) Colby, D. A.; Bergman, R. G.; Ellman, J. A. Rhodiumcatalyzed $\mathrm{C}-\mathrm{C}$ bond formation via heteroatom-directed $\mathrm{C}-\mathrm{H}$ bond activation. Chem. Rev. 2010, 110, 624-655.

(15) Daugulis, O.; Do, H.-Q.; Shabashov, D. Palladium- and copper-catalyzed arylation of carbon-hydrogen bonds. Acc. Chem. Res. 2009, 42, 1074-1086.
(16) Davis, H. J.; Phipps, R. J. Harnessing non-covalent interactions to exert control over regioselectivity and siteselectivity in catalytic reactions. Chem. Sci. 2017, 8, 864-877.

(17) Dey, A.; Agasti, S.; Maiti, D. Palladium catalysed meta-C$\mathrm{H}$ functionalization reactions. Org. Biomol. Chem. 2016, 14, 5440-5453.

(18) Dick, A. R.; Sanford, M. S. Transition metal catalyzed oxidative functionalization of carbon-hydrogen bonds. Tetrahedron 2006, 62, 2439-2463.

(19) Engle, K. M.; Mei, T.-S.; Wasa, M.; Yu, J.-Q. Weak coordination as a powerful means for developing broadly useful C-H functionalization reactions. Acc. Chem. Res. 2012 $45,788-802$.

(20) Gensch, T.; Hopkinson, M. N.; Glorius, F.; Wencel-Delord, J. Mild metal-catalyzed C-H activation: examples and concepts. Chem. Soc. Rev. 2016, 45, 2900-2936.

(21) Lyons, T. W.; Sanford, M. S. Palladium-catalyzed liganddirected $\mathrm{C}-\mathrm{H}$ functionalization reactions. Chem. Rev. 2010, 110, 1147-1169.

(22) Rouquet, G.; Chatani, N. Catalytic functionalization of $\mathrm{C}\left(\mathrm{sp}^{2}\right)-\mathrm{H}$ and $\mathrm{C}\left(\mathrm{sp}^{3}\right)-\mathrm{H}$ bonds by using bidentate directing groups. Angew. Chem. Int. Ed. 2013, 52, 11726-11743.

(23) Wencel-Delord, J.; Dröge, T.; Liu, F.; Glorius, F. Towards mild metal-catalyzed C-H bond activation. Chem. Soc. Rev. 2011, 40, 4740-4761.

(24) Yeung, C. S.; Dong, V. M. Catalytic dehydrogenative cross-coupling: forming carbon-carbon bonds by oxidizing two carbon-hydrogen bonds. Chem. Rev. 2011, 111, 12151292.

(25) Hartwig, J. F.; Larsen, M. A. Undirected, Homogeneous $\mathrm{C}-\mathrm{H}$ Bond Functionalization: Challenges and Opportunities. ACS Cent. Sci. 2016, 2, 281-292.

(26) Kuhl, N.; Hopkinson, M. N.; Wencel-Delord, J.; Glorius, F. Beyond directing groups: transition-metal-catalyzed $\mathrm{C}-\mathrm{H}$ activation of simple arenes. Angew. Chem. Int. Ed. 2012, 51, 10236-10254.

(27) Neufeldt, S. R.; Sanford, M. S. Controlling site selectivity in palladium-catalyzed $\mathrm{C}-\mathrm{H}$ bond functionalization. Acc. Chem. Res. 2012, 45, 936-946.

(28) Wedi, P.; van Gemmeren, M. Arene-Limited Nondirected C-H Activation of Arenes. Angew. Chem. Int. Ed. 2018, 57, 13016-13027.

(29) Cheng, C.; Hartwig, J. F. Rhodium-catalyzed intermolecular $\mathrm{C}-\mathrm{H}$ silylation of arenes with high steric regiocontrol. Science 2014, 343, 853-857.

(30) Cho, J.-Y.; Tse, M. K.; Holmes, D.; Maleczka, R. E.; Smith, M. R. Remarkably selective iridium catalysts for the elaboration of aromatic C-H bonds. Science 2002, 295, 305308.

(31) Ishiyama, T.; Takagi, J.; Ishida, K.; Miyaura, N.; Anastasi, N. R.; Hartwig, J. F. Mild Iridium-Catalyzed Borylation of Arenes. High Turnover Numbers, Room Temperature Reactions, and Isolation of a Potential Intermediate. J. Am. Chem. Soc. 2002, 124, 390-391.

(32) Saito, Y.; Segawa, Y.; Itami, K. para-C-H Borylation of Benzene Derivatives by a Bulky Iridium Catalyst. J. Am. Chem. Soc. 2015, 137, 5193-5198.

(33) Vora, H. U.; Silvestri, A. P.; Engelin, C. J.; Yu, J.-Q. Rhodium(II)-catalyzed nondirected oxidative alkenylation of arenes: arene loading at one equivalent. Angew. Chem. Int. Ed. 2014, 53, 2683-2686.

(34) Ishiyama, T.; Takagi, J.; Hartwig, J. F.; Miyaura, N. A Stoichiometric Aromatic C-H Borylation Catalyzed by Iridium(I)/2,2'-Bipyridine Complexes at Room Temperature. Angew. Chem. Int. Ed. 2002, 41, 3056.

(35) Campeau, L.-C.; Chen, Q.; Gauvreau, D.; Girardin, M.; Belyk, K.; Maligres, P.; Zhou, G.; Gu, C.; Zhang, W.; Tan, L. et al. A Robust Kilo-Scale Synthesis of Doravirine. Org. Process Res. Dev. 2016, 20, 1476-1481. 
(36) Waltz, K. M. Selective Functionalization of Alkanes by Transition-Metal Boryl Complexes. Science 1997, 277, 211213.

(37) Fujiwara, Y.; Moritani, I.; Danno, S.; Asano, R.; Teranishi, S. Aromatic substitution of olefins. VI. Arylation of olefins with palladium(II) acetate. J. Am. Chem. Soc. 1969, 91, 71667169.

(38) Fujiwara, Y.; Asano, R.; Moritani, I.; Teranishi, S. Aromatic substitution of olefins. XXV. Reactivity of benzene, naphthalene, ferrocene, and furan toward styrene, and the substituent effect on the reaction of monosubstituted benzenes with styrene. J. Org. Chem. 1976, 41, 1681-1683.

(39) Jia, C.; Lu, W.; Kitamura, T.; Fujiwara, Y. Highly Efficient Pd-Catalyzed Coupling of Arenes with Olefins in the Presence of tert -Butyl Hydroperoxide as Oxidant. Org. Lett. 1999, 1, 2097-2100.

(40) Zhou, L.; Lu, W. Towards ideal synthesis: alkenylation of aryl C-H bonds by a Fujiwara-Moritani reaction. Chemistry 2014, 20, 634-642.

(41) Chen, H.; Wedi, P.; Meyer, T.; Tavakoli, G.; van Gemmeren, M. Dual Ligand-Enabled Nondirected C-H Olefination of Arenes. Angew. Chem. Int. Ed. 2018, 57, 24972501.

(42) Naksomboon, K.; Valderas, C.; Gómez-Martínez, M.; Álvarez-Casao, Y.; Fernández-Ibáñez, M. Á. S,O-LigandPromoted Palladium-Catalyzed $\mathrm{C}-\mathrm{H}$ Functionalization Reactions of Nondirected Arenes. ACS Catal. 2017, 7, 63426346.

(43) Wang, P.; Verma, P.; Xia, G.; Shi, J.; Qiao, J. X.; Tao, S.; Cheng, P. T. W.; Poss, M. A.; Farmer, M. E.; Yeung, K.-S. et al. Ligand-accelerated non-directed $\mathrm{C}-\mathrm{H}$ functionalization of arenes. Nature 2017, 551, 489-493.

(44) Zhao, D.; Xu, P.; Ritter, T. Palladium-Catalyzed LateStage Direct Arene Cyanation. Chem 2019, 5, 97-107.

(45) Liu, L.-Y.; Yeung, K.-S.; Yu, J.-Q. Ligand-Promoted NonDirected C-H Cyanation of Arenes. Chemistry 2019, 25, 2199 2202.

(46) Chen, H.; Mondal, A.; Wedi, P.; van Gemmeren, M. Dual Ligand-Enabled Nondirected C-H Cyanation of Arenes. ACS Catal. 2019, 9, 1979-1984.

(47) Mondal, A.; Chen, H.; Flämig, L.; Wedi, P.; van Gemmeren, M. Sterically Controlled Late-Stage C-H Alkynylation of Arenes. ChemRxiv 2019, 9250706.

(48) Wang, D.-H.; Engle, K. M.; Shi, B.-F.; Yu, J.-Q. Ligandenabled reactivity and selectivity in a synthetically versatile aryl C-H olefination. Science 2010, 327, 315-319.

(49) Shi, B.-F.; Maugel, N.; Zhang, Y.-H.; Yu, J.-Q. Pd(II)catalyzed enantioselective activation of $\mathrm{C}\left(\mathrm{sp}^{2}\right)-\mathrm{H}$ and $\mathrm{C}\left(\mathrm{sp}^{3}\right)-$ $\mathrm{H}$ bonds using monoprotected amino acids as chiral ligands. Angew. Chem. Int. Ed. 2008, 47, 4882-4886.

(50) Cheng, G.-J.; Yang, Y.-F.; Liu, P.; Chen, P.; Sun, T.-Y.; Li, G.; Zhang, X.; Houk, K. N.; Yu, J.-Q.; Wu, Y.-D. Role of N-acyl amino acid ligands in $\mathrm{Pd}(\mathrm{II})$-catalyzed remote $\mathrm{C}-\mathrm{H}$ activation of tethered arenes. J. Am. Chem. Soc. 2014, 136, 894-897.

(51) Engle, K. M.; Wang, D.-H.; Yu, J.-Q. Ligand-accelerated C$\mathrm{H}$ activation reactions: evidence for a switch of mechanism. J. Am. Chem. Soc. 2010, 132, 14137-14151.

(52) Yang, Y.-F.; Hong, X.; Yu, J.-Q.; Houk, K. N. ExperimentalComputational Synergy for Selective Pd(II)-Catalyzed C-H Activation of Aryl and Alkyl Groups. Acc. Chem. Res. 2017, 50, 2853-2860.

(53) Kubota, A.; Emmert, M. H.; Sanford, M. S. Pyridine ligands as promoters in $\mathrm{Pd}(\mathrm{II} / 0)$-catalyzed $\mathrm{C}-\mathrm{H}$ olefination reactions. Org. Lett. 2012, 14, 1760-1763.

(54) Zhang, Y.-H.; Shi, B.-F.; Yu, J.-Q. Pd(II)-catalyzed olefination of electron-deficient arenes using 2,6dialkylpyridine ligands. J. Am. Chem. Soc. 2009, 131, 50725074 .
(55) Ying, C.-H.; Yan, S.-B.; Duan, W.-L. 2-Hydroxy-1,10phenanthroline vs 1,10-phenanthroline: significant ligand acceleration effects in the palladium-catalyzed oxidative Heck reaction of arenes. Org. Lett. 2014, 16, 500-503.

(56) Emmert, M. H.; Cook, A. K.; Xie, Y. J.; Sanford, M. S. Remarkably high reactivity of $\mathrm{Pd}(\mathrm{OAc})_{2}$ /pyridine catalysts: nondirected C-H oxygenation of arenes. Angew. Chem. Int. Ed. 2011, 50, 9409-9412.

(57) Biswas, B.; Sugimoto, M.; Sakaki, S. C-H Bond Activation of Benzene and Methane by $\mathrm{M}\left(\eta^{2}-\mathrm{O}_{2} \mathrm{CH}\right)_{2}(\mathrm{M}=\mathrm{Pd}$ or Pt). A Theoretical Study. Organometallics 2000, 19, 3895-3908.

(58) Sokolov, V. I.; Troitskaya, L. L.; Reutov, O. A. Asymmetric cyclopalladation of dimethylaminomethylferrocene. J. Organomet. Chem. 1979, 182, 537-546.

(59) Engle, K. M.; Thuy-Boun, P. S.; Dang, M.; Yu, J.-Q. Ligandaccelerated cross-coupling of $\mathrm{C}\left(\mathrm{sp}^{2}\right)$-H bonds with arylboron reagents. J. Am. Chem. Soc. 2011, 133, 18183-18193.

(60) Cheng, G.-J.; Chen, P.; Sun, T.-Y.; Zhang, X.; Yu, J.-Q.; Wu, Y.-D. A combined IM-MS/DFT study on Pd(MPAA)-catalyzed enantioselective $\mathrm{C}-\mathrm{H}$ activation: relay of chirality through a rigid framework. Chemistry 2015, 21, 11180-11188.

(61) Dendele, N.; Bisaro, F.; Gaumont, A.-C.; Perrio, S.; Richards, C. J. Synthesis of a [2.2]paracyclophane based planar chiral palladacycle by a highly selective kinetic resolution/C-H activation reaction. Chem. Commun. 2012, 48, 1991-1993.

(62) Günay, M. E.; Ilyashenko, G.; Richards, C. J. Models for the basis of enantioselection in palladium mediated $\mathrm{C}-\mathrm{H}$ activation reactions. Tetrahedron Asymmetry 2010, 21, 2782-2787.

(63) Günay, M. E.; Richards, C. J. Synthesis of Planar Chiral Phosphapalladacycles by N-Acyl Amino Acid Mediated Enantioselective Palladation. Organometallics 2009, 28, 5833-5836.

(64) Haines, B. E.; Musaev, D. G. Factors Impacting the Mechanism of the Mono-N-Protected Amino Acid LigandAssisted and Directing-Group-Mediated C-H Activation Catalyzed by Pd(II) Complex. ACS Catal. 2015, 5, 830-840.

(65) Musaev, D. G.; Figg, T. M.; Kaledin, A. L. Versatile reactivity of Pd-catalysts: mechanistic features of the mono$\mathrm{N}$-protected amino acid ligand and cesium-halide base in Pdcatalyzed C-H bond functionalization. Chem. Soc. Rev. 2014 43, 5009-5031.

(66) Hennessy, E. J.; Buchwald, S. L. Synthesis of substituted oxindoles from alpha-chloroacetanilides via palladiumcatalyzed C-H functionalization. J. Am. Chem. Soc. 2003, 125, 12084-12085.

(67) Mota, A. J.; Dedieu, A.; Bour, C.; Suffert, J. Cyclocarbopalladation involving an unusual 1,5-palladium vinyl to aryl shift as termination step: theoretical study of the mechanism. J. Am. Chem. Soc. 2005, 127, 7171-7182.

(68) Gómez, M.; Granell, J.; Martinez, M. VariableTemperature and -Pressure Kinetics and Mechanism of the Cyclopalladation Reaction of Imines in Aprotic Solvent. Organometallics 1997, 16, 2539-2546.

(69) Campo, M. A.; Huang, Q.; Yao, T.; Tian, Q.; Larock, R. C. 1,4-palladium migration via $\mathrm{C}-\mathrm{H}$ activation, followed by arylation: synthesis of fused polycycles. J. Am. Chem. Soc. 2003, 125, 11506-11507.

(70) Capito, E.; Brown, J. M.; Ricci, A. Directed palladation: fine tuning permits the catalytic 2-alkenylation of indoles. Chem. Commun. 2005, 1854-1856.

(71) Catellani, M.; Chiusoli, G. P. Palladacycle formation by electrophilic aromatic substitution, as monitored by ${ }^{1} \mathrm{H}$ NMR spectroscopy. J. Organomet. Chem. 1992, 425, 151-154.

(72) Hughes, C. C.; Trauner, D. Concise Total Synthesis of (-)Frondosin B Using a Novel Palladium-Catalyzed Cyclization. Angew. Chem. Int. Ed. 2002, 41, 1569-1572. 
(73) Lane, B. S.; Brown, M. A.; Sames, D. Direct palladiumcatalyzed C-2 and C-3 arylation of indoles: a mechanistic rationale for regioselectivity. J. Am. Chem. Soc. 2005, 127, 8050-8057.

(74) Park, C.-H.; Ryabova, V.; Seregin, I. V.; Sromek, A. W.; Gevorgyan, V. Palladium-catalyzed arylation and heteroarylation of indolizines. Org. Lett. 2004, 6, 1159-1162.

(75) Zhang, S.; Shi, L.; Ding, Y. Theoretical analysis of the mechanism of palladium(II) acetate-catalyzed oxidative Heck coupling of electron-deficient arenes with alkenes: effects of the pyridine-type ancillary ligand and origins of the metaregioselectivity. J. Am. Chem. Soc. 2011, 133, 20218-20229.

(76) Kozuch, S.; Martin, J. M. L. The rate-determining step is dead. Long live the rate-determining state! Chemphyschem 2011, 12, 1413-1418.

(77) Simmons, E. M.; Hartwig, J. F. On the interpretation of deuterium kinetic isotope effects in $\mathrm{C}-\mathrm{H}$ bond functionalizations by transition-metal complexes. Angew. Chem. Int. Ed. 2012, 51, 3066-3072.

(78) Lapointe, D.; Fagnou, K. Overview of the Mechanistic Work on the Concerted Metallation-Deprotonation Pathway. Chem. Lett. 2010, 39, 1118-1126.

(79) Davies, D. L.; Donald, S. M. A.; Macgregor, S. A. Computational study of the mechanism of cyclometalation by palladium acetate. J. Am. Chem. Soc. 2005, 127, 13754-13755.

(80) Steinhoff, B. A.; Guzei, I. A.; Stahl, S. S. Mechanistic characterization of aerobic alcohol oxidation catalyzed by $\mathrm{Pd}(\mathrm{OAc})_{2}$ /pyridine including identification of the catalyst resting state and the origin of nonlinear catalyst dependence. J. Am. Chem. Soc. 2004, 126, 11268-11278.

(81) Cook, A. K.; Sanford, M. S. Mechanism of the palladiumcatalyzed arene $\mathrm{C}-\mathrm{H}$ acetoxylation: a comparison of catalysts and ligand effects. J. Am. Chem. Soc. 2015, 137, 3109-3118.

(82) Steinhoff, B. A.; Stahl, S. S. Ligand-Modulated Palladium Oxidation Catalysis: Mechanistic Insights into Aerobic Alcohol Oxidation with the $\mathrm{Pd}(\mathrm{OAc})_{2}$ /Pyridine Catalyst System. Org. Lett. 2002, 4, 4179-4181.

(83) Schultz, M. J.; Adler, R. S.; Zierkiewicz, W.; Privalov, T.; Sigman, M. S. Using mechanistic and computational studies to explain ligand effects in the palladium-catalyzed aerobic oxidation of alcohols. J. Am. Chem. Soc. 2005, 127, 8499-8507.

(84) Izawa, Y.; Stahl, S. S. Aerobic Oxidative Coupling of oXylene: Discovery of 2-Fluoropyridine as a Ligand to Support Selective Pd-Catalyzed C-H Functionalization. Adv. Synth. Catal. 2010, 352, 3223-3229.

(85) Engle, K. M. The mechanism of palladium(II)-mediated $\mathrm{C}-\mathrm{H}$ cleavage with mono-N-protected amino acid (MPAA) ligands: origins of rate acceleration. Pure Appl. Chem. 2016, 88, 119-138.

(86) Gair, J.; Haines, B. E.; Filatov, A. S.; Musaev, D. G.; Lewis, J. C. Di-Palladium Complexes are Active Catalysts for MonoN-Protected Amino Acid Accelerated Enantioselective C-H Functionalization. ChemRxiv 2019, 7665734.

(87) Deprez, N. R.; Sanford, M. S. Synthetic and mechanistic studies of Pd-catalyzed $\mathrm{C}-\mathrm{H}$ arylation with diaryliodonium salts: evidence for a bimetallic high oxidation state $\mathrm{Pd}$ intermediate. J. Am. Chem. Soc. 2009, 131, 11234-11241.

(88) Gair, J. J.; Haines, B. E.; Filatov, A. S.; Musaev, D. G.; Lewis, J. C. Mono-N-protected amino acid ligands stabilize dimeric palladium(II) complexes of importance to $\mathrm{C}-\mathrm{H}$ functionalization. Chem. Sci. 2017, 8, 5746-5756.

(89) Giri, R.; Liang, J.; Lei, J.-G.; Li, J.-J.; Wang, D.-H.; Chen, X.; Naggar, I. C.; Guo, C.; Foxman, B. M.; Yu, J.-Q. Pd-catalyzed stereoselective oxidation of methyl groups by inexpensive oxidants under mild conditions: a dual role for carboxylic anhydrides in catalytic $\mathrm{C}-\mathrm{H}$ bond oxidation. Angew. Chem. Int. Ed. 2005, 44, 7420-7424.
(90) Powers, D. C.; Benitez, D.; Tkatchouk, E.; Goddard, W. A.; Ritter, T. Bimetallic reductive elimination from dinuclear Pd(III) complexes. J. Am. Chem. Soc. 2010, 132, 14092-14103. (91) Powers, D. C.; Geibel, M. A. L.; Klein, J. E. M. N.; Ritter, T. Bimetallic palladium catalysis: direct observation of $\mathrm{Pd}(\mathrm{III})$ Pd(III) intermediates. J. Am. Chem. Soc. 2009, 131, 1705017051.

(92) Hill, D. E.; Pei, Q.-l.; Zhang, E.-X.; Gage, J. R.; Yu, J.-Q.; Blackmond, D. G. A General Protocol for Addressing Speciation of the Active Catalyst Applied to LigandAccelerated Enantioselective C( $\left.\mathrm{sp}^{3}\right)-\mathrm{H}$ Bond Arylation. ACS Catal. 2018, 8, 1528-1531.

(93) Halpern, J. Mechanism and stereoselectivity of asymmetric hydrogenation. Science 1982, 217, 401-407.

(94) Stejskal, E. 0.; Tanner, J. E. Spin Diffusion Measurements: Spin Echoes in the Presence of a Time Dependent Field Gradient. J. Chem. Phys. 1965, 42, 288-292. (95) Li, D.; Keresztes, I.; Hopson, R.; Williard, P. G. Characterization of reactive intermediates by multinuclear diffusion-ordered NMR spectroscopy (DOSY). Acc. Chem. Res. 2009, 42, 270-280.

(96) Jang, H. B.; Rho, H. S.; Oh, J. S.; Nam, E. H.; Park, S. E.; Bae, H. Y.; Song, C. E. DOSY NMR for monitoring self aggregation of bifunctional organocatalysts: increasing enantioselectivity with decreasing catalyst concentration. Org. Biomol. Chem. 2010, 8, 3918-3922.

(97) Subramanian, H.; Jasperse, C. P.; Sibi, M. P. Characterization of Brønsted acid-base complexes by ${ }^{19} \mathrm{~F}$ DOSY. Org. Lett. 2015, 17, 1429-1432.

(98) Li, Z.; Han, Y.; Jin, F.; Gao, Z.; Gao, Z.; Ao, L.; Wang, F. Bisalkynylplatinum(II) terpyridine molecular tweezer with conformationally-rigid spacer: modulating the binding selectivity in a three-component supramolecular recognition system. Dalton Trans. 2016, 45, 17290-17295.

(99) Motiwala, H. F.; Charaschanya, M.; Day, V. W.; Aubé, J. Remodeling and Enhancing Schmidt Reaction Pathways in Hexafluoroisopropanol. J. Org. Chem. 2016, 81, 1593-1609.

(100) Liu, Q.; Wu, H.; Zhang, L.; Zhou, Y.; Zhang, W.; Pan, X.; Zhang, Z.; Zhu, X. RAFT polymerization of $\mathrm{N}$-vinylpyrrolidone mediated by cyanoprop-2-yl-1-dithionaphthalate in the presence of a fluoroalcohol: the possibility of altering monomer properties by hydrogen bonding? Polym. Chem. 2016, 7, 2015-2021.

(101) Quantitative characterisation of the hydrogen bonding behaviour on the acceptor functions in oligopeptide derivatives with a fluorinated alcohol. J. Chem. Soc., Perkin Trans. 2 2002, 186-191.

(102) Yang, Y.-F.; Cheng, G.-J.; Liu, P.; Leow, D.; Sun, T.-Y.; Chen, P.; Zhang, X.; Yu, J.-Q.; Wu, Y.-D.; Houk, K. N. Palladiumcatalyzed meta-selective $\mathrm{C}-\mathrm{H}$ bond activation with a nitrilecontaining template: computational study on mechanism and origins of selectivity. J. Am. Chem. Soc. 2014, 136, 344-355.

(103) TURBOMOLE V7.2 2017, a development of University of Karlsruhe and Forschungszentrum Karlsruhe $\mathrm{GmbH}$, 1989-2007, TURBOMOLE GmbH, since 2007; available from http://www.turbomole.com.

(104) Perdew, J. P.; Ernzerhof, M.; Burke, K. Rationale for mixing exact exchange with density functional approximations. Phys. Rev., B Condens. Matter 1996, 105, 9982-9985.

(105) Adamo, C.; Barone, V. Toward reliable density functional methods without adjustable parameters: The PBE0 model. J. Chem. Phys. 1999, 110, 6158-6170.

(106) Zhao, Y.; Truhlar, D. G. Design of density functionals that are broadly accurate for thermochemistry, thermochemical kinetics, and nonbonded interactions. J. Phys. Chem. A 2005, 109, 5656-5667.

(107) Lotz, M. D.; Camasso, N. M.; Canty, A. J.; Sanford, M. S. Role of Silver Salts in Palladium-Catalyzed Arene and 
Heteroarene C-H Functionalization Reactions.

Organometallics 2017, 36, 165-171.

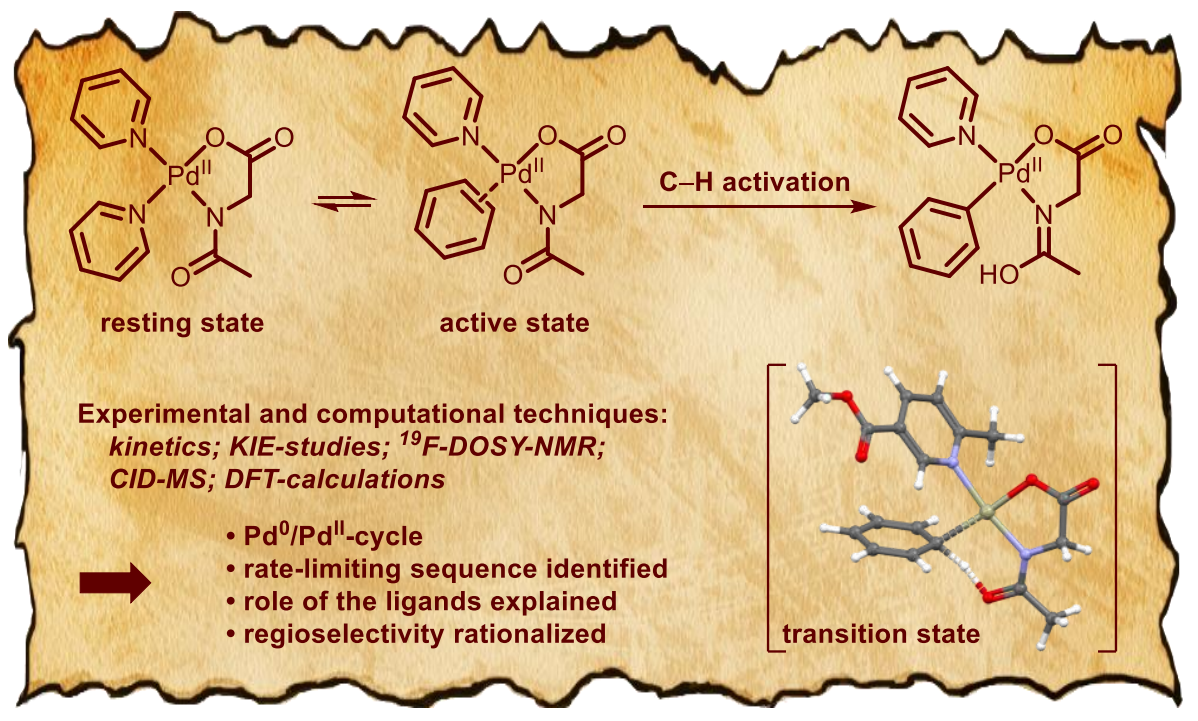

